\title{
Principal Component Analyses and Scalp Distribution of the Auditory P150-250 and N250-550 to Speech Contrasts in Mexican and American Infants
}

\author{
Maritza Rivera-Gaxiola, Juan Silva-Pereyra, \\ Lindsay Klarman, and Adrian Garcia-Sierra \\ Institute for Learning and Brain Sciences (I-LABS) and \\ Department of Speech and Hearing Sciences \\ University of Washington, Seattle \\ Lourdes Lara-Ayala and Cesar Cadena-Salazar \\ Autonomous University of Queretaro, Mexico \\ Patricia Kuhl \\ Institute for Learning and Brain Sciences (I-LABS) and \\ Department of Speech and Hearing Sciences \\ University of Washington, Seattle
}

\begin{abstract}
We report a Principal Component Analysis (PCA) and the scalp distribution of the normalized peak amplitude values for speech-related auditory Event-related Potentials (ERP) P150-250 and N250-550 in 7-, 11-, and 20-month-old American infants learning English and in 10-13-month-old Mexican infants learning Spanish. After assessing the infant auditory ERP P-N complex using PCA, we evaluated the topographic distribution of each of the discriminatory phases to native and non-native CV-syllabic contrasts used in Spanish and English. We found that the first two Principal Components for each contrast type across ages showing a maximization of differences between the P150-250 and the N250-550 waves, explain more than $70 \%$ of the variance. The scalp distributions of the P150-250 and N250-550 components also differed, the P150-250 showing a frontal and anterior temporal distribution, and the N250-550 a more posterior distribution. The older infants showed a broader distribution of
\end{abstract}

Correspondence should be addressed to Maritza Rivera-Gaxiola, Insitute for Learning and Brain Sciences (I-LABS) and Department of Speech and Hearing Sciences, University of Washington, Box 357988, Seattle, WA 98195. E-mail: rivegaxi@u.washington.edu 
responses, particularly for the N250-550. There were no differences in the topographies of the components between same-aged Mexican and American infants. We discuss the perceptual/linguistic functions that each component may reflect during development and across the two cultures.

Speech perception is the process of creating a linguistically meaningful perceptual experience from otherwise meaningless vocalizations or, in the case of sign language, from movements of our hands and arms. To be able to segment sentences and extract meaning from words, phrases, and general discourse, one has to represent the speech signal and be able to differentiate subtle differences between speech sounds. How do infants accomplish these tasks and how does this occur in the brain? There are data suggesting that infants are programmed to calculate statistical probabilities of the presentation of speech sounds and attend, for example, to prosodic and phonotactic patterns in order to extract words (Juszcyk et al., 1994; Mehler et al., 1994; Mehler et al., 1996; Saffran et al., 1996; Maye et al., 2002; Saffran \& Thiessen, 2003). It is also known that infants' abilities to perceive speech sounds change dramatically over the first years of life and it is now well established that experience with specific linguistic patterns and gestures exerts a profound effect on an individual's ability to identify and discriminate speech sounds (Jusczyk, 1997; Kuhl et al., 1992; Werker \& Tees 1984a; Kuhl, 2004). Not all languages share and use the same physical/acoustic differences to convey differential meaning: for example, the distinction between $/ \mathrm{r} /$ and $/ 1 /$, is not used in Japanese to express different words. Japanese speakers produce a sound which is in between the English sounds /ra/ and /la/, closer to the acoustic properties of the English /la/. The acoustic cue used to distinguish between $/ \mathrm{d} /$ and $/ \mathrm{t} /$ or between $/ \mathrm{b} /$ and $/ \mathrm{p} /$, for example, is different in Spanish and in English. Spanish speakers use a prevoiced/voiceless (or short lag) distinction, whereas American listeners use a voiceless (or short lag)/aspirated, long lag distinction. At the behavioral level, it has been well established that after the first half year of life foreign (non-native) speech sound discrimination declines (Werker \& Tees, 1984a,b; Best, 1994; Kuhl, 2000) and native phoneme discrimination improves (Kuhl et al., 1992; Kuhl et al., 2006; Tsao et al., 2006). For example, Japanese 10-12-month-old infants and more mature listeners experience great trouble perceiving the difference between the words "rip" and "lip" (Miyawaki et al., 1975; Buchwald et al., 1994). Adult English listeners, on the other hand, have difficulty perceiving the difference between the Spanish words "dos" and "tos" ("two" and "cough", respectively). However, 6-8-month-old infants do not experience such trouble discriminating phonetic contrasts used or not in the language of their environment. They display similar discriminatory capacities regardless of prior exposure. Werker and her colleagues have interpreted these findings as the product of reorganization in perceptual biases, rather than as a total loss in absolute discriminatory abilities occurring in the 
first year of life (Werker \& Tees, 1984a, 1984b). Kuhl and her collaborators (see Kuhl, 2004 for a review) have more recently proposed that extensive experience with a primary language causes a neural commitment to the acoustic properties of that language, hence the acoustic patterns that do not conform to the previously exposed ones become difficult to discriminate. In this view, native language neural commitment (NLNC) is necessary for further language development (Kuhl, 2004). Although there is growing understanding of the neural basis underlying the organization, reorganization and commitment of the auditory/cortical space in relation to speech, these topics are greatly understudied. The literature documents important physiological correlates of, for example, the discriminatory process in the adult as well as developmentally (for reviews, see Cheour et al., 1998b; Morr et al., 2002 and Eggermont \& Ponton, 2001), but much work remains before we reach the point of developing a robust theory that explains how the human brain accomplishes linguistic tasks both in the adult as well as ontogenetically.

The non-invasive technique most widely used to study the infant brain in action while processing speech is the recording of the electroencephalogram or EEG and the subsequent description of event-related potentials (ERPs) derived from these recordings. In this domain, one of the most widely described ERP components in the native/foreign speech perception literature is the Mismatch Negativity (MMN) response. The MMN is a difference waveform elicited by random, occasional changes in unattended sounds (Näätänen et al., 1978). However, the MMN reflects more than the passive mechanism that signals physical differences between two sounds: the weight of acoustic or phonetic dominance in any given speech contrast will be affected by attention and relevance of the task, this in turn, affects MMN peak latency, amplitude or even presence/absence and potential overlapping of components. MMNs are elicited by different stimulus attributes, and different attribute-specific generators have been suggested. Most studies have shown that infants, adults, and school-aged children display MMNs to syllables that lie between and within a linguistic category, but the amplitudes and scalp distributions can differ between conditions (Kraus et al., 1995; Maiste et al., 1995; Näätänen et al. 1997; Cheour et al., 1998b, Kraus et al., 1999; Rivera-Gaxiola et al., 2000a; Morr et al., 2002). Other components have also been reported during passive paradigms, for example a Late Positive Deflection has been observed to highly salient/prototypical native contrasts (Rivera-Gaxiola et al., 2000b). Finally, the widely studied P300 has also been described for speech discrimination during active tasks. Buchwald and colleagues (1994) showed that Japanese speakers do not display a P300 to a/rip/-/lip/word contrast, while they clearly do so to a /ba/- /pa/ syllabic contrast. Maiste and her colleagues (1995) also observed a P300 in the across- but not-within-category condition when testing adults in an active task of CV-syllable discrimination. Differences have also been reported in the polarity of the ERP discriminatory responses that infants display when presented with speech contrasts or tones at different probabilities. Cheour and colleagues (1998b), for example, report clear MMNs to native and 
foreign vowel contrasts. Other researchers (e.g., Dehaene-Lambertz and Dehaene, 1994; Dehaene-Lambertz et al., 2002; Pikho et al., 1999; Leppänen et al., 1999; Winkler et al., 2003) have reported the discriminatory phase of the ERP to be reflected as positive components of the waveforms they observe. Morr and colleagues (2002) report positivities and negativities in the same children, and using an "MMN paradigm," Leppänen and colleagues (2004) recently reported differences in polarity in newborns depending on their developmental stage.

In a series of longitudinal, cross-sectional, and cross-linguistic studies using $\mathrm{CV}$-syllables presented in a double-oddball paradigm where native and foreign contrasts are tested simultaneously, we (Rivera-Gaxiola et al., 2004; RiveraGaxiola et al., 2005 a, 2005b; Rivera-Gaxiola et al., submitted) have reported differences in amplitude and latency in the two most prominent infant auditory ERP deflections to standard and deviant stimuli; namely, an initial positivity that peaks around $150-250 \mathrm{msec}$ after stimulus onset and the subsequent negativity, peaking around 250-550 msec after stimulus onset. We have also shown that 10-13month-old babies learning English or Spanish show larger negativities (N250-550) to native deviants than to the standard. The same infants show either larger P150-250s ("P"-responders) or larger N250-550 ("N"-responders) to non-native deviants with respect to the standard [Rivera-Gaxiola et al., (2005a and b), Rivera-Gaxiola et al., submitted]. Both "P" and "N"-responders were also observed as early as 7 months of age. In other words, the P150-250 and the N250-550 deflections were present in all infants, but the discriminatory response was reflected over the P150-250 time window for some infants and over the N250-550 time window for other infants. This was not a clear-cut distinction from the difference MMN waveforms. Finally, 20-month-old babies learning English only displayed N250-550 amplitude differences between standard and either deviant, but the difference was larger for the native deviant than for the foreign deviant with respect to the standard (Rivera-Gaxiola et al., 2004). Given these developmental and cross-linguistic results, we have proposed the P150-250 discriminatory phase to be related more to acoustic processing than with a drift in attention that other authors have hypothesized for a positivity peaking around 200-350 msec (Ceponiene et al., 2002, Kushnerenko et al., 2002a,b). The N250-550 phase is, in our view, the response component related to phonetic difference processing. Furthermore, we also observed (Rivera-Gaxiola et al., 2005b) that the so-called "P"-responders produce a significantly larger number of words at 18, 22, 25, 27, and 30 months of age when evaluated with the MacArthur Communicative Development Inventories (CDIs). These same infants also score higher in morpheme and sentence complexity than the "Nresponders" (Klarman et al., 2004). Both behavioral (Conboy et al., 2005; Kuhl et al., 2005) and ERP data (Kuhl et al, in press) indicate a negative correlation between the capacity to discriminate foreign contrasts and concomitant word comprehension or later word production/comprehension. Responding to the foreign contrast at the P150-250 level (allegedly "acoustic"), and at the N250-550 level to 
the native contrast (allegedly "phonetic") is advantageous for monolingual first language learning. Responding "phonetically" to both contrast types (like the "N"-responders at 11 months of age) negatively affects the infant's performance in later mother-language tasks. These findings indicate sensitive early time periods for exploring how the children are neurally processing native and foreign phonemes and "wiring" themselves accordingly. Remaining less committed to the native language(s), and more "open" to foreign languages that are not experienced may be indicative of a slower pace of language development (Rivera-Gaxiola et al., 2005b; Kuhl et al., in press), supporting the NCNL hypothesis (Kuhl, 2004).

In sum, the type of stimuli, the dimensions of physical difference, paradigms, ages and procedures used have to be considered to explain the polarity and latency of the discriminatory response differences reported across studies and laboratories. We believe that the polarity differences we have reported may indicate important individual biological variability that cannot be observed when ERPs are evaluated only at the group level. It is therefore very valuable when the same stimuli, paradigm, testing procedures, and methods of analyses can be used across development and across populations allowing the nature of each of the responses to be studied and interpreted more thoroughly. In this report, we present new analyses of data from 7-, 11-, and 20-month-old infants learning English and 10-13-month-old infants learning Spanish who were tested in our laboratories using identical protocols. Our main goal with the present analyses is to further test our notion that the classification of response patterns as "P" and "N" provides a useful tool for understanding speech discrimination from 7-20 months of age and for predicting later language outcomes. We applied Principal Component Analyses (PCA), a powerful method for determining the componential structure of ERPs (see Molfese et al., 2001 for a review) to these data. We also analyzed the scalp distribution of the between-subjects' normalized peak amplitudes of the P150-250 and the N250-550 for each age and linguistic environment group separately. We predicted that the PCA would show that the factors accounting for most of the variability in our recordings are due to differences in the amplitudes to the deviant stimuli over the P150-250 and/or N250-550 time windows. Regarding the topographic distribution, we hypothesized the following: An equal topographic distribution of these deflections across the scalp and/or ages could imply that the same neural structures (single generator) are active during the processing of the stimuli differences and that this single generator rotates in time, yielding the differences in polarity inversion over time. The differences in amplitude over the P150-250 or the N250-550 could be reflecting strength of response at either time window, before or after the rotation. On the other hand, different scalp distributions across the scalp and/or ages will support our interpretation that they are different components subserving different purposes, thus informing us further regarding maturational patterns involved in the responses. 


\section{MATERIALS AND METHODS}

\section{Data}

The ERP data from studies by Rivera-Gaxiola et al., (2004; 2005a and b; submitted) were used for the present analyses. These ERPs were obtained from 7-, 11-, and 20-month-old infants learning English and 10-13-month-old Mexican infants learning Spanish. They were all tested in sound attenuated rooms and passively listened to CV-syllables presented in a double-oddball paradigm (80/10/10 proportion, 1000 stimuli in total) where the syllable common to both Spanish and English was used as a standard and the deviants were the language specific to Spanish or English (see Table 1 below); that is, both contrast types were then tested within the same time series. The EEG was recorded continuously and ERPs determined off-line.

Figure 1 illustrates the larger amplitude to the deviants (dashed and bold lines) with respect to the standard in the participants who show the "P"-responses and in the "N"-responses of our studies.

\section{Participants}

ERPs from normally developing American Infants learning English in monolingual households were evaluated: 16 infants ( 8 girls) aged 7 months (range 6.24-7.2 months), 28 infants (16 girls) aged 11 months (range 10.23-11.6 months) and 15 infants ( 9 girls) aged 20 months (range 19.3-20.5 months).
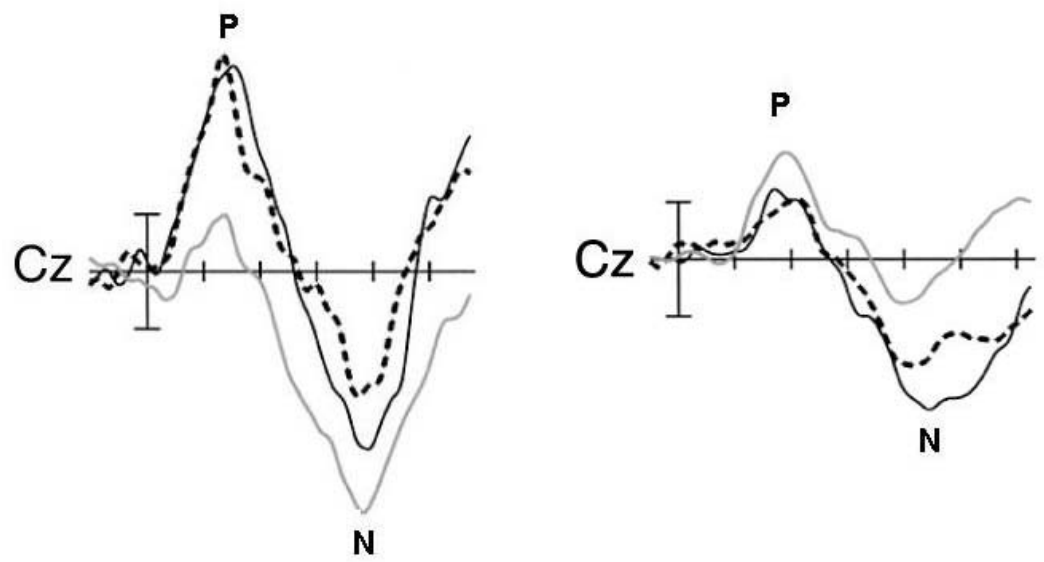

FIGURE 1 This figure shows the grand-averages of subjects who show the "P-responses" (left) and the "N-responses" (right). Dotted and bold lines correspond to ERPs to deviants, and the continuous gray line is the ERP to the standard. Positive is plotted up $(5 \mu \mathrm{V})$ and time scale is $100 \mathrm{msec}$ per tick. 
ERPs from normally developing Mexican Infants learning Spanish in monolingual households were evaluated: 17 infants ( 9 girls) aged 10-13 months (range 10.1-13.5 months).

The criteria for inclusion in the study were that infants were being raised in monolingual households (Spanish in Mexico and English in the U.S.), had no known visual or auditory deficits, were full term (born \pm 14 days from due date) and normal birth weight (6-10 lbs.). Mothers must have had normal pregnancies and deliveries, and no history of hearing loss or language impairment could be present in immediate family members.

\section{Stimuli}

Three consonant-vowel syllables differing in voice-onset time (VOT) were used: a Spanish pre-voiced lead/da/, a Spanish/ta/-English /da/ (short lag) and an English aspirated [tha] (long lag) (Table 1).

These were naturally produced stimuli by a female Spanish/English bilingual speaker and manipulated using Praat and SoundForge 4.0 to obtain a match in duration $(229.65 \pm 0.3 \mathrm{msec})$, intensity, and average RMS power. The average fundamental frequency was $180 \mathrm{~Hz}$. Pilot studies confirmed that native English speakers behaviorally discriminated the English but not the Spanish contrast (Table 1).

A double-oddball paradigm was used and a total of 1,000 stimuli were delivered. The phoneme common to both languages (English 'da'/ Spanish 'ta') was used as the standard and the two language-specific sounds (English [tha], Spanish $/ \mathrm{da} /$ ) served as deviants in an 80/10/10 presentation proportion. The deviant stimuli appeared in a semi-random fashion with at least three standards between deviants. The inter-stimulus interval was $700 \mathrm{msec}$. There was a $1 \mathrm{~min}$ silent period inserted every 2 min of stimulation. Stimuli ( $69 \mathrm{~dB}$ SPL) were delivered to two loudspeakers placed $\mathrm{lm}$ in front of the child.

\section{EEG Recordings}

The electroencephalogram was recorded using electrocaps with pre-inserted tin Ag/AgCI electrodes from Fpl, Fp2, F3, F4, C3, C4, P3, P4 01, 02, F7, F8, T3,

TABLE 1

Stimuli Used and Their General Physical Properties

\begin{tabular}{lcllll}
\hline & ERP Paradigm & & & Voice-onset & \\
Syllable Used & Status & Phonetic Use & Aspiration & Time & Lead/lag \\
\hline$/ \mathrm{da} /$ & deviant & Spanish & unaspirated & $-24 \mathrm{msec}$ & Lead \\
$\mathrm{Sp} / \mathrm{ta} /-$ Eng/da/ & standard & Spanish \& English & unaspirated & $12 \mathrm{msec}$ & Short lag \\
{$\left[\mathrm{t}^{\mathrm{h}} \mathrm{a}\right]$} & deviant & English & aspirated & $46 \mathrm{msec}$ & Long lag \\
\hline
\end{tabular}


T4, T5, T6, Fz, Cz, Pz , and the active right mastoid and referenced to the left mastoid (10/20 International system). The vertical electro-oculogram (VEOG) was recordedfrom 1 infra-orbital electrode placed on the infant's left cheek. The amplifier bandwidth for EEG collection was set between 0.1 and $40 \mathrm{~Hz}$ and signals were amplified with a gain of 20,000. All electrode impedances were kept at or below 5KQ. EEG was sampled every 4 msec. Segments with large eye movements, blinks or other artifacts were automatically eliminated (segments with electrical activity $+/-150 \mathrm{pV}$ at any electrode site were rejected). EEG segments of $700 \mathrm{msec}$ with a pre-stimulus baseline time of $100 \mathrm{msec}$ were selected and averaged off-line to obtain the ERPs. Baseline correction was performed in relation to the pre-stimulus time. Further low-pass filtering was set at $15 \mathrm{~Hz}$. The average number of trials for each deviant type and standard stimuli from each subject's ERPs for each age-group and population was 75 .

\section{Statistical Analysis}

The P150-250 and N250-550 peak amplitudes were first identified each using the following definitions: the P- peak will be the maximum positive between 150 and 250 msec after stimulus onset at each electrode site; the $\mathrm{N}$ peak will be the maximum negative amplitude between $350-550 \mathrm{msec}$ after stimulus onset at the same electrode sites. Peak amplitude and peak latency measurements were computed for each subject, experimental condition (native and foreign contrasts) and wave peak $(\mathrm{P}$ and $\mathrm{N})$. The amplitude data were then normalized between subjects over all recording sites according to the McCarthy \& Wood (1985) procedure for the topographical distribution analysis.

A standard spatial Principal Component Analyses with VARIMAX rotation with Kaiser normalization as available in SPSS was carried out. The peak amplitude values of the deviants from each child (all ages), and waveforms (P150-250 and N250-550) over each recording site were entered separately for each condition (native and foreign). The retention criterion for the number of components was eigenvalues $>1$.

For the topographical analysis, repeated-measures analyses of variance (rmANOVAs) were conducted for each deflection with age (7, 11, 10-13 Mex and 20 months), Deviant Phonetic Status (native or foreign), Hemisphere (left and right), and Electrode Site (Fpl-Fp2, F3-F4, C3-C4, P3-P4, 01-02, F7-F8, T3-T4, T5-T6) as factors. The Greenhouse-Geisser correction was applied to analyses with more than one degree of freedom in the numerator. The Tukey's Honestly Significant Difference (HSD) method was used for post-hoc pairwise comparisons in the repeated-measures analyses. 


\section{RESULTS}

\section{PCA}

Our Principal Component Analyses show that the two main factors for the native condition explain $73 \%$ of the variance and $70.17 \%$ for the foreign condition: A plot of the factor loadings using the VARIMAX rotation method of each component can be seen in Figure 2. These results demonstrate a maximization of the differences between the P150-250 and the N250-550 peaks, regardless of age.

\section{Topographic Distribution}

The comparison between normalized peak amplitude values of the P150-250 and the N250-550 in response to the native deviant across ages and linguistic environment is shown in Figure 3.

There were no significant hemispheric differences $(p>0.05)$; however, an age $\times$ deviant phonetic status $\times$ electrode site interaction was found $F(8.971212 .3)=2,7$, $p=0.005)$. For the native deviant, the largest amplitudes of the $\mathrm{P} 150-250$ peaks were observed in the oldest children over frontal and anterior temporal sites, whereas the largest amplitudes of the N250-550 peaks were over parietal sites across ages.

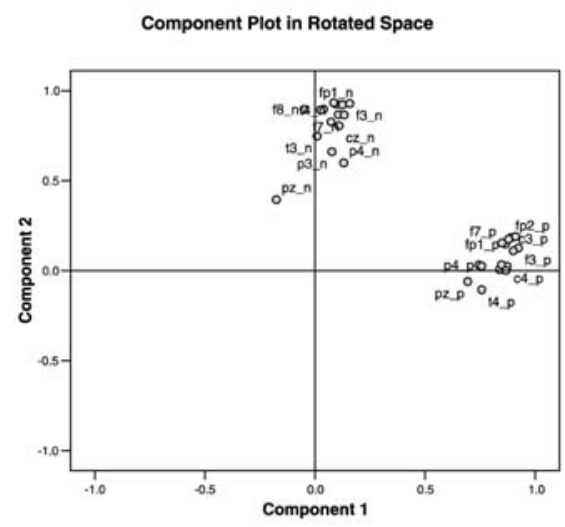

a) Native

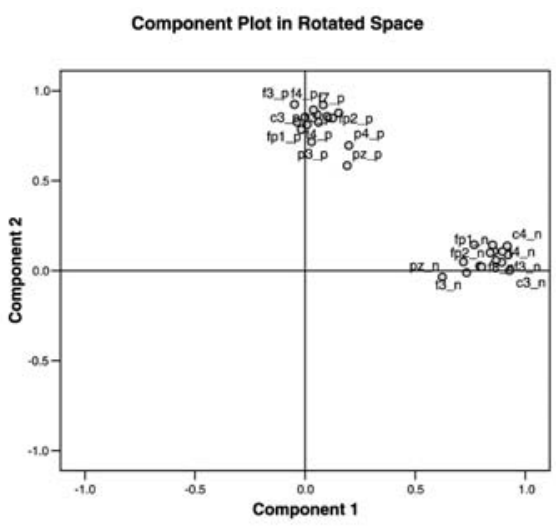

b) Foreign

FIGURE 2 Factor loadings for the (a) Native P150-250 and N250-550 values and (b) Foreign P150-250 and N250-550 values are plotted and components 1 and 2 are shown. 
The comparison between normalized peak-amplitude values of the P150-250 and the N250-550 in response to the foreign deviant across ages and linguistic environment is shown in Figure 4.

A distribution similar to that for the native deviant was observed for the P150-250 and the N250-550 peaks in response to the foreign deviant across ages, i.e., there was an Age $\times$ Deviant Phonetic Status $\times$ Electrode site interaction $F(1113,263.32)=1.9, p=0.037$. Again, the largest amplitudes for the P150-250 were seen in the 20 month-old toddlers over frontal areas. The same trend was observed for the N250-550 values, except that these peaks were largest over parietal
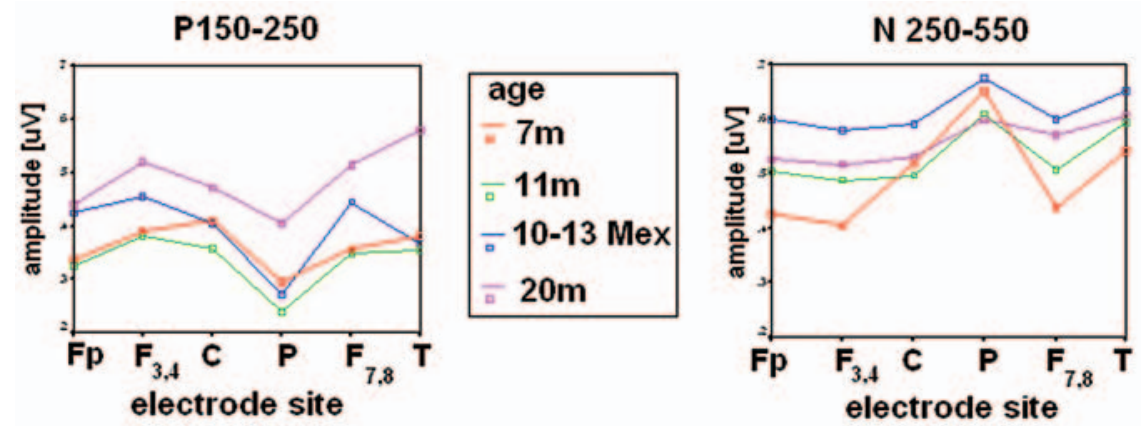

FIGURE 3 Topographic distribution for the normalized peak amplitude values of the native deviant responses over the P150-250 (left) and the N250-550 (right) regions for each group of infants (7 months, 11 months, 10-13 Mexican infants and 20 months). Amplitude values over Fronto-polar (Fp), anterior Frontal (F 3.4), Central (C), Parietal (P), posterior Frontal (F 7.8) and Temporal (T) derivations are shown.
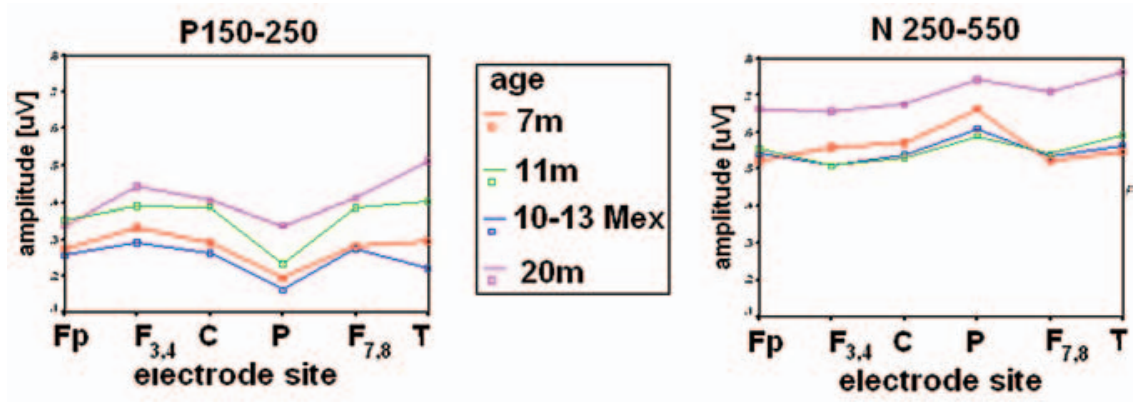

FIGURE 4 Topographic distribution for the normalized peak amplitude values of the foreign deviant responses over the P150-250 (left) and the N250-550 (right) regions for each group of infants (7 months, 11 months, 10-13 Mexican infants and 20 months). Amplitude values over Fronto-polar (FP), anterior Frontal (F3.4), Central (C), Parietal (P) posterior Frontal (F7.8) and Temporal (T) derivations are shown. 
areas. In both deviant phonetic conditions (native and foreign), the N250-550 peaks are more broadly spread in the 20-month-old infants with respect to the other age groups. No differences were encountered between Spanish 10-13-month-old infants'- and the English 11-month-old learning infants' P150-250 or N250-550 distributions.

\section{DISCUSSION AND CONCLUSION}

We previously reported a series of analyses showing that the infant auditory P150-250 and N250-550 responses to native and foreign CV-syllables differ in polarity, latency, and that the amplitude differences in either discriminatory phase had an impact on later language development. Our previous reports explored amplitude differences between standard and each type of deviant (native and foreign). We made a consistent qualitative observation that some infants had larger differences between the standard and deviant over the P150-250 phase, while others showed larger differences over the N250-550 time-window. These differences in amplitude were validated with various types of parametric and non-parametric statistical measures, as well as behavioral correlates. We decided that further analyses were required to investigate the componential structure of our data set, as well as potential scalp distribution differences. In the present paper, we further explored the structure of our data by carrying out a spatial Principal Component Analysis and a topographical distribution analysis. As a multivariate statistical procedure which reduces the number of variables or dimensional space, we predicted that the differences in the amplitudes to the deviant over the P150-250 and/or N250-550 time windows would be reflective of most of the variance in our data. The different scalp distributions across the scalp and/or ages would support our interpretation that the P150-250 and the N250-550 are different components subserving different purposes.

The PCA showed that the two factors that explain more than $70 \%$ if the variance are precisely the P150-250 and the N250-550 amplitude values across ages over the different electrode sites. We also show that these positive and negative components have different scalp topographic distributions supporting the notion that these may originate from different sources. We know that the brain acts as a volume conductor and that voltages measured at any particular point in time and scalp location may represent the activity of multiple generators in the brain. However, different components have specific topographies, occur over particular periods of time and are related in characteristic ways to the experimental manipulations (see Picton et al., 2000). Our present topographical analysis results, taken together with our previous reports, are strongly suggestive of the activation of two different generators during the Spanish/English VOT double oddball paradigm in infants aged 7 to 20 months, but it is definitely too early to speculate about the precise location of this generators 
within the brain. Other recording, sensor digitizing, and mathematical tools are necessary to approach source localization, especially in infants.

In our analyses, the largest P150-250s were found over frontal and anterior temporal recording sites. Dehaene-Lambertz and Baillet (1998) have also reported a frontal distribution for the P-peak they see as the discriminatory response that young infants display to phonetic contrasts. The largest N250-550 responses we observed, on the other hand, were over parietal recording sites. No group differences were found between either P150-250s or N250-550s for the Spanish and English learning infants. This is important because it means that infants from two different cultures, English-learning and Spanish-learning, neurally respond in a similar way to their native and narrative sounds, even though these sounds are physically different in two different cases. For Spanish learners, the pre-voiced $/ \mathrm{da} /$ is the native deviant, and the aspirated /tha/ is the foreign deviant, whereas for English learners the reverse is true, yet the infants responded similarly to their respective native and foreign deviants. This means that the responses reported are related to the phonetic status each deviant has for the infant depending on the language of their environment.

In general terms, the amplitudes of both P150-250 and N250-550 we observed are more homogeneously distributed in the foreign deviant comparison than in the native deviant comparison, regardless of age. We observed a more focalized distribution of the N250-550, especially for the native comparison. However, the developmental trend seems to be reversed from other reports: 7 month-old infants display larger N250-550s over parietal sites than over any other recording site. The 20-month-old infants' N250-550s definitely have a broader topographic distribution, although still larger amplitudes over P3 and P4 (see Figure 3). It is important to underscore the fact that these results are not based on difference waveforms. In this respect, we cannot strictly compare our results to those reported for topographic distributions of the MMN effect, although this has been reported to be largest over right frontal recording sites in adults and mainly over $\mathrm{Fz} / \mathrm{Cz}$ in younger infants (for example see Näätänen et al., 1997; Cheour et al., 1998a,b; Morr et al., 2002). The focal- to-distributed pattern is of interest to our understanding of the possible neural reorganization or differential neural commitment. Since only the oldest group (our 20-month-old babies) responds over the N250-550 time window for both contrast types, we assume this is the "more mature" way of responding, ${ }^{1}$ and interpret our findings as indicating differences in the number or organization of structures involved in processing phonetic stimuli with age. The fact that we also observed some infants responding only at the N-level to both contrast types as

\footnotetext{
${ }^{1}$ If difference waveforms were to be used, this group of infants would have shown an MMN-type of response around similar latencies of those reported. Given that this is the response observed more consistently later in life, this further supports our view that responding over the N250-550 time window for both contrast types is a more mature way of responding.
} 
early as 11 months of age, and that this in turn negatively impacted their later language scores, supports Kuhl's NLNC model: why recruit more areas for the foreign sounds at this stage? There should be a neural commitment to the native language only during this period. Our findings also give support to Werker and Tees (1984b) theory in which 10-12 months of age is a phase where major sensori-neural reorganization is taking place; our results show that there is still variability regarding the type of discriminatory response (P150-250 or N250-550), and recruiting more areas for native contrasts as opposed to remaining "open" to all contrasts at this age impacts later language development (Rivera-Gaxiola et al., 2005a, 2005b, Kuhl et al., in press). We know that 8-month-old infants, for example, listen to more phonetic detail than those at 14 months even when native sounds are being used (Stager \& Werker, 1997).

Furthermore, it is not until 18-20 months of age that they use their very fine phonetic abilities in new word learning tasks (Werker \& Fennel, 2004), by which time we observe the broader distribution of the N250-550, as well as the N250-550 native/N250550 foreign combination of responses. The adequate mapping of nonsense sounds onto word meaning may require larger processing areas.

In summary, even in the face of the limitations of ERPs and their analyses, we have here furthered our understanding of the ERP responses reported in our previous studies. We continue to believe that grouping participants according to whether they display larger amplitudes over the P150-250 or over the N250-550 time windows at 7 or 10-13 months of age is a useful way to analyse their maturity and continue to understand the nature of the physiological responses we are recording with such exquisite time resolution. In our view, the differences we have reported are important in the description of neural circuitry maturation, not only at an ERP level, but also for the detection of potential risk in later language development. This may also be another step toward understanding why some children perform better than others on more complex language tasks, yet lie well within normal ranges. It is yet to be seen whether these findings also have an impact on second language learning since remaining non-committed to a specific set of acoustic patterns may be useful for easier acquisition of a second language. Challenges also remain in understanding the associated behavioral correlates of each type of response.

\section{ACKNOWLEDGMENTS}

Participation in this symposium was supported by USDA CRIS 6521-51000-002-03S. The authors wish to acknowledge grants to PKK from NIH (HD 37954), the University of Washington's Institute for Learning and Brain Sciences, and supprt from the NSF's Science of Learning Center (the LIFE Center) at the University of 


\section{Washington. We also thank Kathryn Norwood, Denise Padden and Robin Cabanis for their assistance during the study.}

\section{REFERENCES}

Best, C. (1994). The emergence of native-language phonological influences in infants: a perceptual assimilation model. In: J. C. Goodman \& H. C. Nusbaum (Eds.), The development of speech perception: the transition from speech sounds to spoken words (pp. 167-224). Cambridge, MA: MIT Press.

Buchwald, J. S., Guthrie, D., Schwafel, J., Erwin, R.J., \& Vanlancker, D. (1994). Influence of Language structure on brain-behavior development. Brain and Language, 46, 607-619.

Ceponiene, R., Shestakova, A., Balan, P., Alku, P., Yaguchi, K., \& Näätänen, R. (2002). Maturation of cortical sound processing as indexed by event-related potentials. Clinical Neurophysiology, 113, 870-882.

Cheour, M., Alho, K., Ceponiene, R., Reinikainen, K., Sainio, K., Pohjavouri, M., et al. (1998a). Maturation of mismatch negativity in infants. International Journal of Psychophysiology., 29, 217-226.

Cheour, M., Ceponiene, R., Lehtokoski, A., Luuk, A., Allik, J., Alho, K., et al. (1998b). Development of language-specific phoneme representations in the infant brain. Nature Neuroscience, 1, 351-353.

Cheour-Luhtanen, M., Alho, K., Kujala, T., Sainio, K., Reinikainen, K., Renlund, M., et al. (1995). Mismatch negativity indicates vowel discrimination in newborns. Hearing Research, 82, 53-58.

Conboy, B., Rivera-Gaxiola, M., Klarman, L., Akseylu, E., \& Kuhl, P. K. (2005). Associations between native and nonnative speech sound discrimination and language development at the end of the first year. In A. Brugos, M. R. Clark-Cotton, \& S. Ha (Eds.), Supplement to the Proceedings of the 29th Boston University Conference on Language Development.

Dehaene-Lambertz, G., \& Dehaene, S. (1994). Speed and cerebral correlates of syllable discrimination in infants. Nature, 370, 292-295.

Dehaene-Lambertz, \& Baillet, S. (1998). A phonological representation in the infant brain. NeuroReport, 9(8), 1885-1888.

Dehaene-Lambertz, G., Dehaene, S., \& Hertz-Pannier, L. (2002). Electrophysiological evidence for automatic phonetic processing in neonates. NeuroReport, 12, 3155-3158.

Eggermont, J. J. \& Ponton, C. W. (2001). The neurophysiology of auditory perception: from single units to evoked potentials. Audiology and Neuro-otology, 7, 71-99.

Jusczyk, P. D. (1997). The discovery of spoken language. Cambridge, MA: MIT Press.

Jusczyk, P., Luce, P., \& Charles-Luce, J. (1994). Infant's sensitivity to phonotactic patterns in the native language. Journal of Memory and Language, 33, 630-645.

Klarman, L., Rivera-Gaxiola, M., Conboy, B., \& Kuhl, P. K. (2004). Event-related potentials to speech: individual variation and vocabulary growth. Poster presented at the Society for Neuroscience Meeting, San Diego, CA.

Kraus, N., Koch, D. B., McGee, T. J., Nicol, T. G., Cunningham, J. (1999). Speech-sound discrimination in school-age children: psychophysical and neurophysiologic measures. Journal of Speech Language and Hearing Research, 42,1042-60.

Kraus, N., McGee, T., Carrell, T. D., Sharma, A. (1995). Neurophysiologic measures of speech discrimination. Ear and Hearing, 16, 19-37.

Kuhl, P. K. (1992). Psychoacoustics and speech perception: Internal standards, perceptual anchors, and prototypes. In L. A. Werner \& E. W. Rubel (Eds.), Developmental psychoacoustics (pp. 293-332). Washington, DC: American Psychological Association.

Kuhl, P. K. (2000). A new view of language acquisition. Proceedings of the National Academy of Sciences of the United States of America, 97, 11850-11857. 
Kuhl, P. K. (2004). Early language acquisition: cracking the speech code. Nature Reviews Neuroscience, 5, 831-843.

Kuhl, P. K., Conboy, B. T., Coffey-Corina, S., Padden, D., Rivera-Gaxiola, M., \& Nelson, T. (In press). Phonetic perception as a pathway to language: New data and Native Language Magnet theory expanded (NLM-e). Philosophical Transactions of the Royal Society B.

Kuhl, P. K., Conboy, B. T., Padden, D., Nelson, T., \& Pruitt, J. (2005). Early speech perception and later language development: Implications for the "Critical Period." Language Learning and Development, 1, 237-264.

Kuhl, P. K., Stevens, E., Hayashi, A., Deguchi, T., Kiritani, S., \& Iverson, P. (2006). Infants show a facilitation effect for native language phonetic perception between 6 and 12 monhts. Developmental Science, 9, F13-F21.

Kuhl, P. K., Tsao, F-M., \& Liu, H-M. (2003). Effects of foreign-language exposure in infancy on phonetic perception. Proceedings of the National Academy of Sciences of the United States of America, 100, 9096-9101.

Kuhl, P. K., Williams, K. A., Lacerda, F, Stevens, K. N., \& Lindblom, B. (1992). Linguistic experience alters phonetic perception in infants by 6 months of age. Science, 255, 606-608.

Kurtzberg, D., Vaughan, H. G. J., Kreuzer, J. A., \& Fliegler, K. Z. (1995). Developmental studies and clinical application of mismatch negativity: Problems and prospects. Ear and Hearing, 16, 105-117.

Kushnerenko, E.V. (2003). Maturation of the cortical auditory event-related brain potentials in infancy. Unpublished doctoral dissertation. University of Helsinki.

Kushnerenko, E., Ceponiene, R., Balan, P., Fellman, V., Huotilainen, M., \& Näätänen, R. (2002b). Maturation of the auditory event-related potentials during the first year of life. NeuroReport, 13, 47-51.

Kushnerenko, E., Ceponiene, R., Balan, P., Fellman, V., Huotilainen, M., \& Winkler, I. (2001). Event-related potential correlates of sound duration: similar pattern from birth to adulthood. NeuroReport, 12, 3777-3781.

Kushnerenko, E., Ceponiene, R., Balan, P., Feliman, V., \& Näätänen, R. (2002a). Maturation of the auditory change detection response in infants: a longitudinal ERP study. NeuroReport, 13, 1843-1848.

Leppänen, P. H., Guttorm T. K., Pihko E., Takkinen S., Eklund K.. \& Lyytinen H. (2004). Maturational effects on newborn ERPs measured in the mismatch negativity paradigm. Experimental Neurology, 190, S91-S 101.

Leppänen, P. H. Y., Pihko, E., Eklund, K. M., \& Lyytinien, H. (1999). Cortical responses of infants with and without a genetic risk for dyslexia: II group effects. NeuroReport, 10, 969-973.

Maiste, A. C., Wiens, A., Hunt, M. J., Scherg, M., Picton, T. W. (1995). Event-related potentials and the categorical perception of speech sounds. Ear and Hearing, 16, 68-90.

Maye, J., Werker, J., \& Gerken, L. (2002). Infant sensitivity to distributional information can affect phonetic discrimination. Cognition, 82, B101-B111.

McCarthy, G., \& Wood, C. C. (1985). Scalp distributions of event-related potentials: An ambiguity associated with analysis of variance models. Electroencephalography and Clinical Neurophysiology, 62, 203-208.

Mehler, J., Bertoncini, J., Dupoux, E., \& Pallier, Ch. (1996). The role of suprasegmentals in speech perception and acquisition. In T. Otake \& A. Cutler (Eds.), Phonological structure and language processing: Cross-linguistic studies (pp. 145-169). New York: Mouton de Gruyter.

Mehler, J., Dupoux, E., Pallier, C., \& Dehaene-Lambertz, G. (1994). Cross-linguistic approaches to speech processing. Current Opinion in Neurobiology, 4, 171-176.

Miyawaki, K., Strange, W., Verbrugge, R., Liberman, A. M., Jenkins, J. J. \& Fujimura, O. (1975). An effect of Linguistic Experience: the discrimination of /r/ and /1/ by native speakers of Japanese and English. Perception and Psychophysics, 18, 331-340.

Molfese, D., Molfese, V. J., \& Kelly, S. (2001). The use of brain electrophysiology techniques to study language: a basic guide for the beginning consumer of electrophysiology information. Learning Disabilities Quarterly, 24, 177-188. 
Morr, M., Shafer, V., Kreuzer, J. A., \& Kurtzberg, D. (2002). Maturation of mismatch negativity in typically developing infants and preschool children. Ear and Hearing, 23, 118-136.

Näätänen, R., Gaillard, A. W. K., \& Mantysalo, S. (1978). Early selective attention effects on the evoked potential: A critical review and reinterpretation. Biological Psychology, 8, 81-136.

Näätänen, R., Lehtokoski, A., Lennes, M., Cheour, M., Huotilainen, M., Iivonen, A. (1997). Language specific phoneme representations revealed by electric and magnetic brain responses. Nature, 385, 432-434.

Picton, T. W., Bentin, S., Berg, P., Donchin, E., Hillyard, S., Johnson, R. Jr., et al. (2000). Guidelines for using human event-related potentials to study cognition: recording standards and publication criteria. Psychophysiology, 37, 127-152.

Pikho, E., Leppänen, P. H., Eklund, K. M., Cheour, M., Gutorm, T. K., \& Lyytinen, H. (1999). Cortical responses of infants with and without a genetic risk for dyslexia: I. Age effects. NeuroReport, 10, 901-905.

Rivera-Gaxiola, M., Csibra, G., Johnson, M. H., \& Karmiloff-Smith, A. (2000a). Electrophysiological correlates of cross-linguistic speech perception in Native English speakers. Behavioural Brain Research, 111, 13-23.

Rivera-Gaxiola, M., Klarman, L., Conboy, B., Aksoylu, E., \& Kuhl, P. K. (2004). Behavior and electrophysiology of cross-linguistic speech perception in 7, 11 and 20 month-old infants. Poster presented at the Society for Neuroscience Meeting, San Diego, CA.

Rivera-Gaxiola, M., Klarman, L., Garcia-Sierra, A., \& Kuhl, P. K. (2005b). Neural patterns to native and non-native speech contrasts in 11 month-old American infants. NeuroReport, 16, 495-498.

Rivera-Gaxiola, M., Lara-Ayala, L., Cadena, C., Jackson-Maldonado, D., \& Kuhl, P. K. (n.d.). Event-related Potentials to an English/Spanish syllabic contrast in Mexican 10-13-month-old infants. Submitted for publication.

Rivera-Gaxiola, M., Silva-Pereyra, J., \& Kuhl, P. K. (2005a). Brain potentials to native and nonnative speech contrasts in 7 and 11 month old American infants. Developmental Science, 8, 162-172.

Rivera-Gaxiola, M., Csibra, G., Johnson, M. H., \& Karmiloff-Smith, A. (2000b). Electrophysiological correlates of category goodness. Behavioural Brain Research, 112, 1-11.

Saffran, J. R. \& Thiessen, E. D. (2003). Pattern induction by infant language learners. Developmental Psychology, 39, 484-494.

Saffran, J. R., Aslin, R. N., \& Newport, E. (1996). Statistical learning by 8-month-old infants. Science, 274, 1926-1928.

Stager, C. L., \& Werker, J. F. (1997). Infants listen for more phonetic detail in speech perception than in word learning tasks. Nature, 388, 381-82.

Tsao, F. M., Liu, H. M., \& Kuhl, P. K. (2004). Speech perception in infancy predicts language development in the second year of life: a longitudinal study. Child Development, 75, 1067-1084.

Werker, J. F. \& Fennel, C. E. (2004). Weaving a Lexicon. In G. Hall \& S. Waxman (Eds.), From listening to sounds to listening to words: Early steps in word learning (pp. 79-109). Cambridge, MA: MIT Press.

Werker, J. F., \& Tees, R. C. (1984a). Cross-language speech perception: Evidence for perceptual reorganization during the first year of life. Infant Behavior \& Development, 7, 49-63.

Werker, J. F., \& Tees, R. C. (1984b). Phonemic and phonetic factors in adult cross-language speech perception. Journal of the Acoustical Society of America, 75, 1866-1878.

Winkler, I., Kushnerenko, E., Horväth, J., Ceponiene, R., Fellman, V., Huotilainen, M., et al. (2003). Newborn infants can organize the auditory world. Proceedings of the National Academy of Sciences of the United States of America, 100, 11812-11815. 